Fractais, Congruências e Primos:

\title{
Uma Estratificação Visual dos Números Inteiros via Fractais de Sierpinski
}

\author{
ISAAC V. S. RODRIGUES ${ }^{1 *}$, JUSCELINO BEZERRA ${ }^{2}$ \\ e LÚCIA MARIA DOS S. PINTO ${ }^{3}$
}

Recebido em 16 de setembro de 2019 / Aceito em 7 de agosto de 2020

\begin{abstract}
RESUMO. Neste trabalho construímos um painel visual enumerado usando fractais do tipo Sierpinski $n$ gons [8] com o objetivo de analisar algumas sequências de números inteiros, principalmente a sequência dos números primos e algumas de suas subsequências clássicas, como os Primos de Sophie Germain. Essa estrutura visual gera uma estratificação de $\mathbb{Z}$ que tem forte ligação com a aritmética modular, tornandose assim um bom painel de visualização para resultados da teoria dos números. Inspirados na construção do Triângulo de Sierpinski por meio do Triângulo de Pascal e pelos trabalhos de Ulam sobre a espiral de primos [9], esta enumeração surgiu naturalmente a partir da geração computacional de fractais $n$-gons onde tomamos como estratégia o algoritmo determinístico citado por Steven Schlicker e Kevin Dennis [8].
\end{abstract}

Palavras-chave: congruência, números primos, $N$-gons, fractais de Sierpinski.

\section{INTRODUÇÃO}

No conjunto dos inteiros, dizemos que $a$ e $b$ são congruentes módulo $n$, e escrevemos $a \equiv b$ $(\bmod n)$ se suas divisões por $n$ dão origem ao mesmo resto. A relação de congruência entre os inteiros é uma relação de equivalência e divide $\mathbb{Z}$ em classes de equivalência. No artigo "The Search for Prime Numbers" [5] de 1982, Pomerance apresenta a aritmética modular como um sistema de cálculos com aplicações importantes em testes de primalidade e ainda traz uma excelente forma para visualizar esta aritmética:

\footnotetext{
*Autor correspondente: Isaac Victor S. Rodrigues - E-mail: isaacvictorsrodrigues@ gmail.com

${ }^{1}$ Escola Nacional de Ciências Estatísticas, ENCE/IBGE, RJ - E-mail: isaacvictorsrodrigues@gmail.com https://orcid.org/0000-0002-7964-046X

${ }^{2}$ Escola Nacional de Ciências Estatísticas, ENCE/IBGE, RJ - E-mail: juscelino.santos@ibge.gov.br https://orcid.org/0000-0001-6831-4100

${ }^{3}$ Escola Nacional de Ciências Estatísticas, ENCE/IBGE, RJ - E-mail: lucia.pinto@ibge.gov.br https://orcid.org/00000002-7345-6813
} 
Para se chegar a lugares tão distantes do sistema numérico, pode-se usar a roda aritmética, inventada por Carl Friedrich Gauss. Ele formulou a aritmética modular, em que o tamanho absoluto de um número é irrelevante e tudo o que importa é o tamanho do último giro da roda aritmética empregada para alcançar o número.

Pomerance [5], 1982, p. 139, tradução nossa.
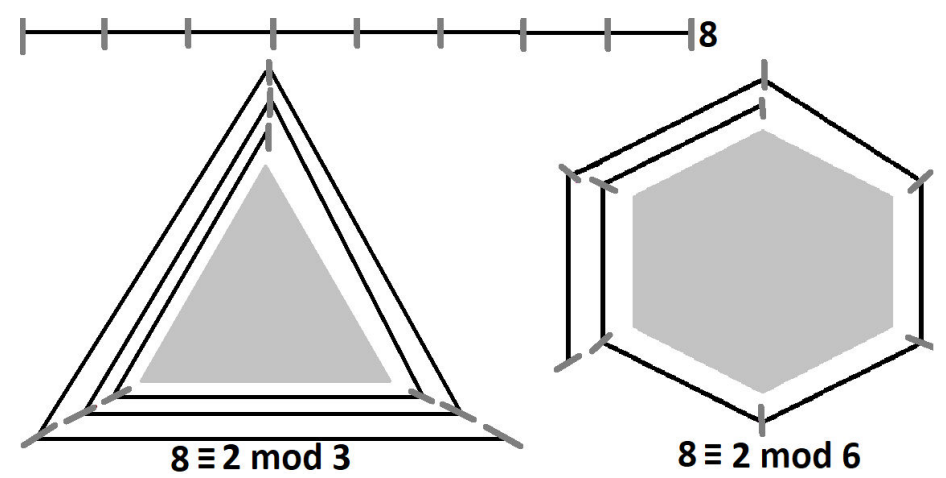

Figura 1: A roda aritmética de Gauss.

Estas rodas são na verdade polígonos regulares com $n$ lados, de forma que se $m$ representa o tamanho absoluto do número e $r$ é o resto da divisão de $m$ por $n, m \equiv r(\bmod n)$ representa o tamanho da última volta parcial necessária para se alcançar $m$ (ver Figura 1). O subconjunto de $\mathbb{Z}$ formado por todos os inteiros que são congruentes a $m$ módulo $n$ é chamado de classe residual, e para uma dada classe residual, o polígono que serve como a roda aritmética descrita por Pomerance faz com que todos os números nesta classe colidam no mesmo vértice do polígono.

Temos assim, uma estratificação de $\mathbb{Z}$ em $n$ subconjuntos, as suas classes residuais ( $\bmod n)$ representadas pelos vértices de um polígono regular de $n$ lados (ver Figura 2). Desta forma, localizar um número nesta estratificação significa identificar o vértice que o contém, e alguns resultados da Teoria dos números, como o Pequeno Teorema de Fermat, podem facilitar esta tarefa (Vide o artigo do Pomerance [5], página 139). Além disso alguns subconjuntos especiais de $\mathbb{Z}$ têm posições que se destacam neste polígono graças as suas características dentro da aritmética modular. Por exemplo, quando estratificamos o conjunto dos inteiros via suas classes residuais módulo 6, em apenas dois dos vértices do hexágono estão localizados os números primos e cada um destes vértices irá concentrar a "mesma" quantidade de primos de acordo com o resultado sobre densidade conhecido como "Teorema dos números primos em Progressões Aritmétricas" (Conforme [7], página 306). 


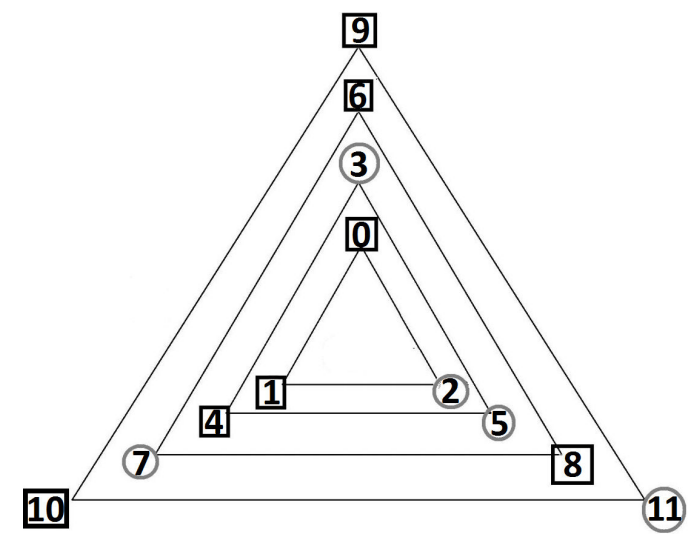

Figura 2: Vértices como classes residuais com primos destacados por círculos e os números compostos por quadrados.

E foi pensando na visualização dos números primos que surgiu a ideia deste trabalho. Questões sobre os números primos, como por exemplo a sua distribuição na reta real ou sua função geradora despertam a curiosidade dos matemáticos desde a antiguidade até os dias atuais, e se tornaram de grande relevância nas últimas décadas devido as suas aplicações em criptografia [3]. Sabe-se, por exemplo, que existem infinitos primos e que a sua distribuição na reta real é bastante irregular. Ao contrário deste comportamento na reta real, a visualização da sequência dos números primos em outras estruturas geométricas indica alguns padrões curiosos.
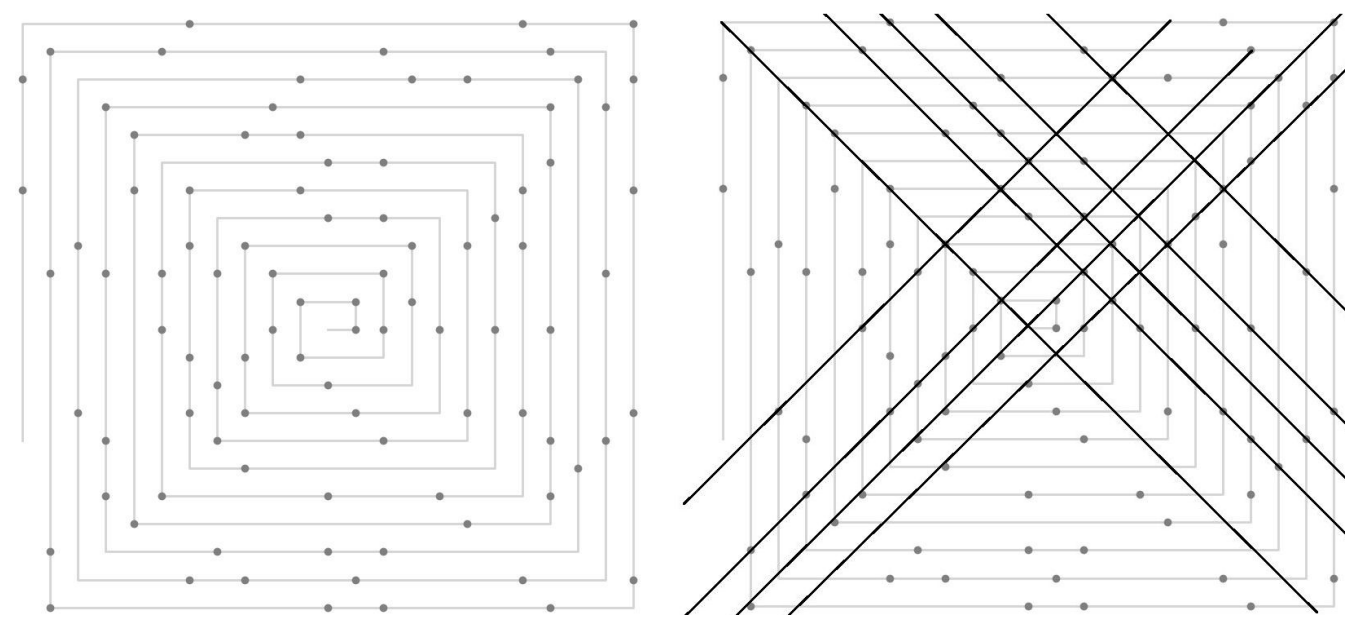

Figura 3: À esquerda a espiral proposta por Ulam com destaque para pontos que representam números primos e à direita destaque para linhas diagonais que passam por números primos.

A espiral de Ulam [9], por exemplo, apresenta uma aparência fortemente não aleatória para a distribuição dos primos onde vemos grande parte destes números se concentrando em linhas 
diagonais do plano (ver Figura 3). Tal estrutura é composta por pontos distintos que seguem uma enumeração e uma regra de construção bastante simples. Assim como o estudo feito por Ulam, o objetivo deste trabalho é construir um painel visual enumerado para identificar visualmente alguns padrões na sequência dos primos. Para este fim, vamos utilizar a estrutura de um fractal $n$-gon ou fractal de Sierpinski [8]. Vale observar que embora o nosso objetivo inicial tenha sido explorar de forma visual alguns resultados importantes sobre a distribuição dos números primos, a estrutura que construímos permite o estudo experimental de outras sequências de inteiros, como os Primos de Sophie Germain.

\section{FRACTAIS DE SIERPINSKI}

Imaginemos o seguinte processo iterativo: começando com um polígono regular de $n$ lados, a cada passo deste processo, explodimos cada um de seus vértices em $n$ vértices igualmente distribuídos satisfazendo: i) estes novos vértices quando ligados formam uma contração do polígono inicial, ii) estes novos polígonos se encaixam "perfeitamente" dentro do polígono que o originou. Isto é uma analogia do passo a passo realizado no processo de construção de fractais do tipo Sierpinski $n$-gons.

A Geometria Fractal traz consigo um forte apelo visual e artístico [4, 10]. Estas formas geométricas possuem algumas características especiais que as distinguem de outras formas da geometria clássica, como por exemplo a auto-similaridade em diferentes níveis de escala, o que significa que um fractal pode ser descrito como a união finita de suas contrações, cópias de menor escala do fractal.

Os Fractais Sierpinski $n$-gons, também conhecidos como $n$-flakes ou ainda como fractais de Dürer, formam uma vasta gama de exemplos que podem ser construídos de forma iterativa por uma regra fixa de substituição geométrica bem definida. Neste texto vamos usar os termos "Fractais de Sierpinski" ou "Fractais $n$-gons", ou apenas " $n$-gons" quando quisermos nos referir aos Fractais do tipo Sierpinski $n$-gons.

O Triângulo de Sierpinski ou 3-gon é construído a partir de um triângulo equilátero onde posicionamos em cada um de seus vértices uma contração deste triângulo, de forma que a figura original se divida igualmente em quatro triângulos equiláteros e o triângulo central seja removido. Na sequência, repete-se o mesmo processo para cada um dos triângulos resultantes como apresentado na Figura 4:

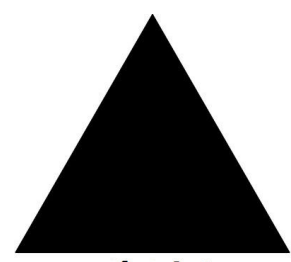

Nível 0

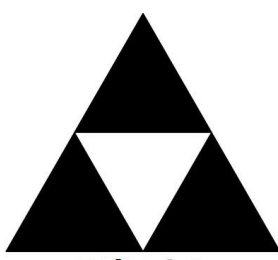

Nível 1



Nível 2

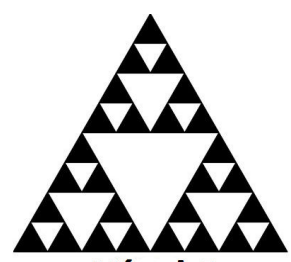

Nível 3

Figura 4: Construção do triângulo de Sierpinski. 
Um outro exemplo bastante explorado neste trabalho e que serve para ilustrar a construção de um n-gon é o hexágono de Sierpinski ou 6-gon. Como um fractal de Dürer, ele é gerado começando com um hexágono regular e à cada iteração posicionamos em cada vértice uma contração (cada vértice explode em 6 novos vértices). Para que os encaixes sejam perfeitos, exige-se ainda que um vértice deste novo hexágono coincida com um vértice do polígono inicial e ao menos outros dois vértices coindicam com os vértices de dois novos polígonos localizados nos vértices vizinhos. $\mathrm{O}$ resultado é ilustrado na Figura 5.

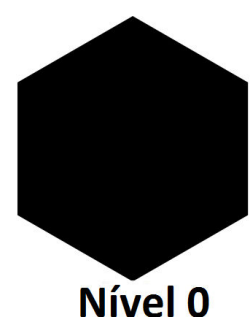

Nível 0

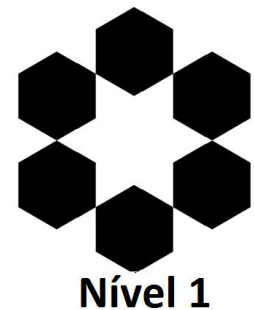

Nível 1

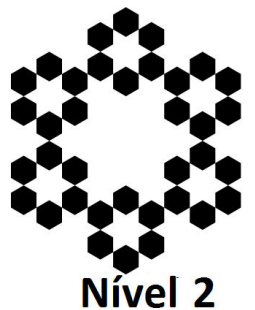

Nível 2

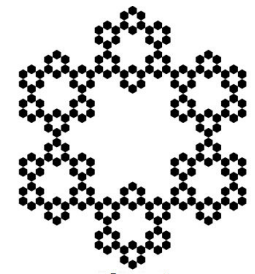

Nível 3

Figura 5: Construção do hexágono de Sierpinski.

\subsection{O algoritmo determinístico}

Apesar de já existirem outras ferramentas gráficas disponíveis na internet para a geração de fractais $n$-gons ${ }^{1}$, foi no desafio de desenvolver um código em linguagem de programação Python que nos deparamos com a enumeração que é o ponto chave da estratificação que vamos apresentar.

Computacionalmente, o processo de gerar um fractal está limitado a um número finito de iterações. Para este fim, utilizamos uma versão do algoritmo conhecido na literatura como Algoritmo Determinístico onde as transformações advém dos procedimentos geométricos (mudança de escala e translações) que geram o fractal como o conjunto atrator de um sistema de funções iteradas (IFS na sigla em inglês) [8]. Uma forma que encontramos de otimizar este algoritmo foi a de olhar estas transformações atuando apenas nos baricentros dos polígonos do nível $i-1$ para que se construa o nível $i$. No que segue, o conjunto formado pelos baricentros será uma representação alternativa do $n$-gon.

Todas as figuras de fractais presentes neste artigo foram construídas a partir de um polígono regular de $n$ lados com vértices $v_{r}=\left(\cos \left(\frac{\pi}{2}+\frac{2 r \pi}{n}\right), \operatorname{sen}\left(\frac{\pi}{2}+\frac{2 r \pi}{n}\right)\right)$, onde $r=0, \cdots, n-1$. Para o encaixe perfeito destes polígonos dentro do polígono inicial, apenas se tocando sem se sobrepor, utilizamos a escolha ótima de um dos parâmetros do algoritmo, o fator de escala. Tal fator define a escala das novas subcópias do fractal com relação ao nível anterior. Na Proposição 1 de [8], Schlicker deduz uma fórmula para esta melhor escolha.

\footnotetext{
${ }^{1}$ Lawrence H. Riddle em seu site " $h t t p:$ // larryriddle. agnesscott. org/", apresenta um programa de construção de fractais "no site, clique em 'IFS Construction Kit'” e também explora a parte teórica da construção de fractais "no site, clique em 'Classic Iterated Function Systems'”.
} 

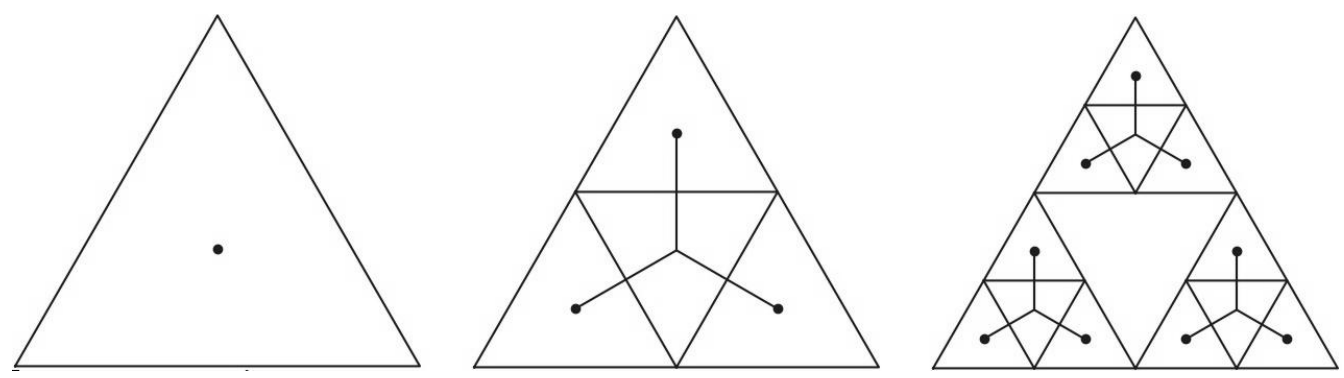

Figura 6: Os baricentros nos três primeiros níveis.

Em nossa versão do Algoritmo Determinístico, posicionamos ordenadamente os novos baricentros em torno dos baricentros do nível anterior seguindo rigorosamente a ordenação imposta pelos índices dos vértices $v_{r}$, o que ficará mais claro na próxima seção. A enumeração é o resultado da forma com que os baricentros do nível $i+1$ são gerados a partir dos baricentros do nível $i$. Abaixo ilustramos a ordem com que estes pontos vão surgindo no Triângulo de Sierpinski nos primeiros níveis.

Na transição do nível 0 para o nível 1:

1. Marque uma posição inicial $\left(X_{0}, Y_{0}\right)$ que representa a posição do baricentro no nível 0 (Passo 00 na Figura 7).

2. Posicione o baricentro acima de $\left(X_{0}, Y_{0}\right)$ (Passo 01 na Figura 7 ).

3. Posicione o baricentro a sudoeste de $\left(X_{0}, Y_{0}\right)$ (Passo 02 na Figura 7 ).

4. Posicione o baricentro a sudeste de $\left(X_{0}, Y_{0}\right)$ (Passo 03 na Figura 7 ).

E de forma análoga, na transição do nível 1 para o nível 2 do triângulo de Sierpinski, estamos posicionando os novos baricentros seguindo a seguinte ordem:

1. Marque as posições $\left(X_{i}, Y_{i}\right)$ cujos índices representam a ordem de construção destes baricentros no nível 1 (Passo 00 na Figura 8).

2. Posicione os baricentros acima dos $\left(X_{i}, Y_{i}\right)$ (Passos 01 à 03 da Figura 8)

3. Posicione os baricentros a sudoeste dos $\left(X_{i}, Y_{i}\right)$ (Passos 04 à 06 da Figura 8)

4. Posicione os baricentros a sudeste dos $\left(X_{i}, Y_{i}\right)$ (Passos 07 à 09 da Figura 8)

\section{DESCREVENDO A ENUMERAÇÃO POR SEUS SUBNÍVEIS}

Nesta seção descreveremos a enumeração a partir das diversas contrações do fractal, que serão nomeadas aqui por níveis e subníveis do $n$-gon. O nível $k$ é o plote obtido após $k$ iterações na 


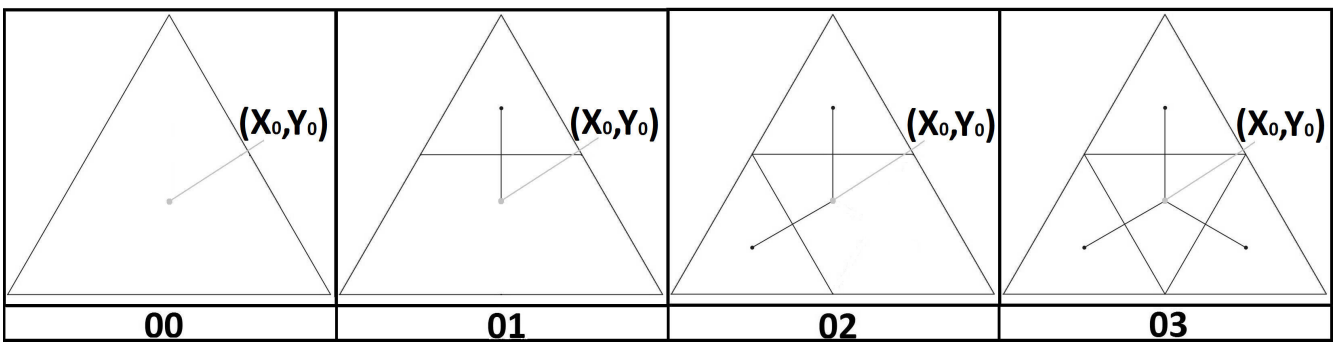

Figura 7: Transição do nível 0 para o nível 1.

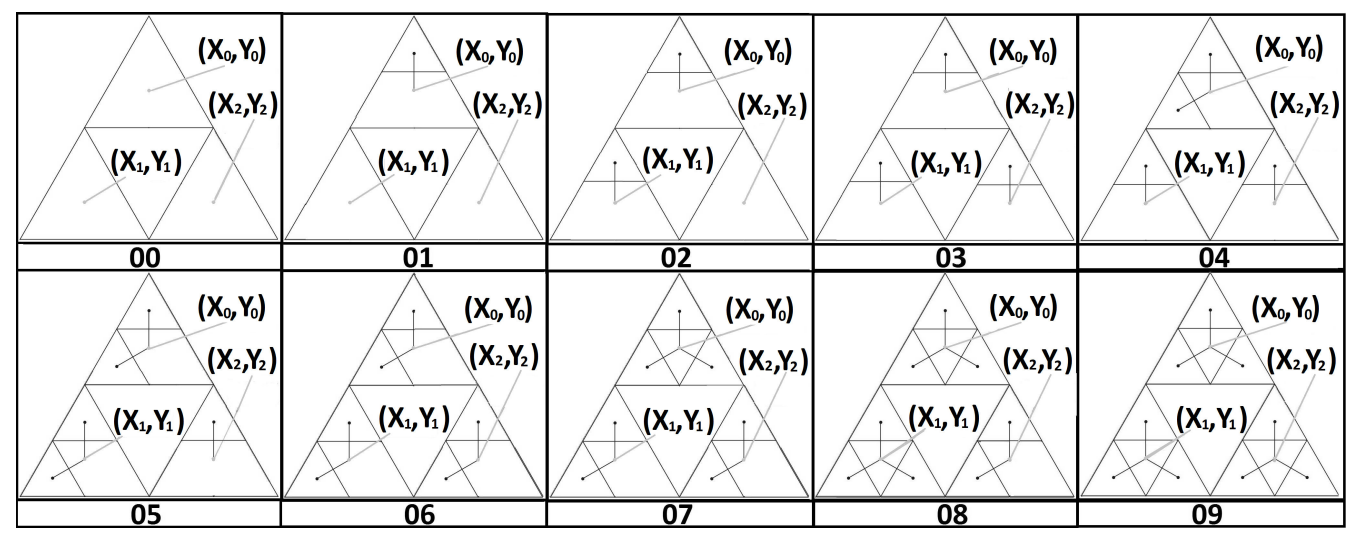

Figura 8: Transição do nível 1 para o nível 2.

construção do $n$-gon. Desta forma, o nível 0 é formado por um polígono, e o nível 1 é formado quando o baricentro do nível 0 explode em $n$ pontos (os baricentros dos polígonos do nível 1) e assim sucessivamente. Um $n$-gon construído iterativamente até o nível $k$ é formado por $n^{k-i}$ cópias do nível $i$, para cada $i \leq k$ (ver Figura 9). Definiremos um subnível de tamanho $i$ como sendo uma cópia do nível $i$ contida no nível $k$ do fractal.

Os subníveis de tamanho 0 são os polígonos (ou baricentros) que formam o desenho do $n$ gon. Desta forma, o plote do nível $k$ de um $n$-gon é formado por $n^{k}$ baricentros e chamaremos de enumeração do $n$-gon a uma enumeração destes pontos. A seguir vamos descrever geometricamente a enumeração gerada pelo algoritmo que utilizamos.

Usaremos um processo indutivo para enumerar o fractal, começando pelo nível 1, onde temos $n$ polígonos distribuídos na forma de um $n$-ágono e que serão enumerados de 0 até $n-1$ a partir do topo e no sentido anti-horário (ver Figura 10A). No passo de indução, vamos enumerar o nível $k+1$ a partir da enumeração do nível $k$, utilizando tal enumeração como uma forma de marcar $n^{k}$ posições em cada um dos subníveis de tamanho $k$ que formam o nível $k+1$. Note que cada uma destas posições aparece $n$ vezes dentro do nível $k+1$ (ver Figura 10B). A ideia é percorrer uma posição por vez, pelos $n$ subníveis de tamanho $k$, até que a posição se esgote e assim passar 


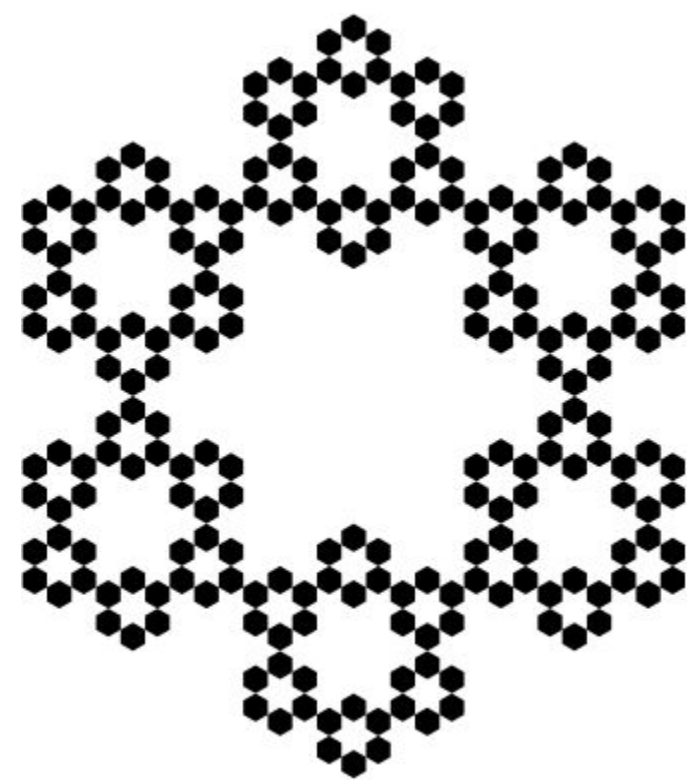

Figura 9: No nível 3 do Hexágono de Sierpinski temos 6 cópias do nível 2, 36 do nível 1 e 216 do nível 0.
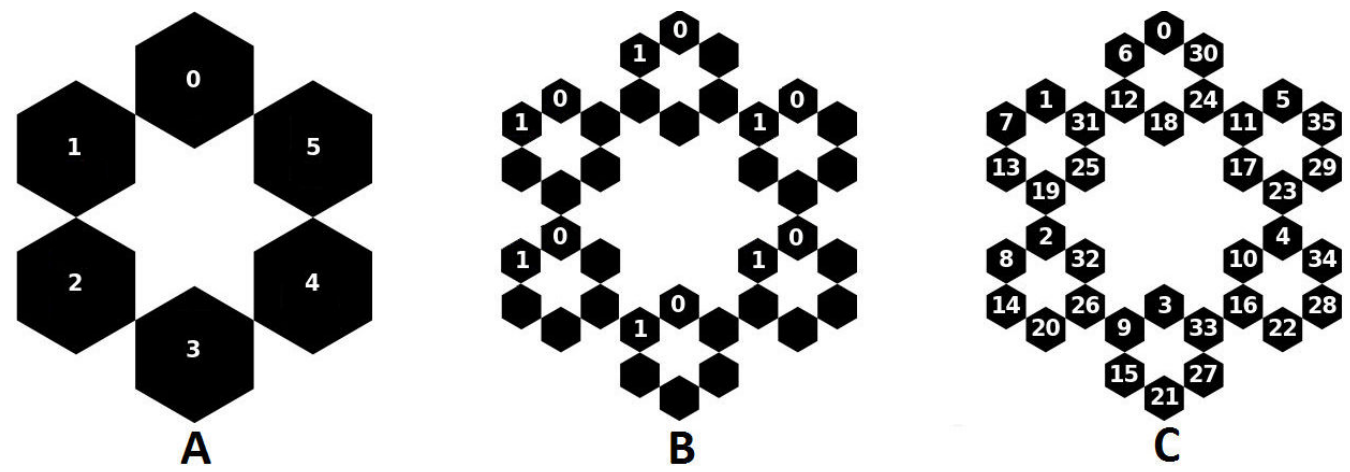

Figura 10: Na Figura 10A temos a enumeração do nível 1 do 6-gon. Já na Figura 10B, temos o nível 2 do 6-gon com as posições 0 e 1 destacadas. A enumeração do nível 2 começará percorrendo a posição 0. Na Figura 10C temos a enumeração do nível 2.

para a posição seguinte, começando com o índice 0 na posição do topo e seguindo no sentido anti-horário até chegar em $n^{k+1}-1$.

Este procedimento pode ser comparado à distribuição num jogo de cartas onde a mesa tem o formato de um hexágono. Por exemplo, se temos 36 cartas para distribuir igualmente por 6 jogadores, com a finalidade de embaralhar mais as cartas é costumeiro ir distribuindo-as uma a uma para cada jogador até que se esgote todas as cartas. Assim, as seis primeiras cartas são 
distribuídas uma para cada jogador. As próximas seis cartas da mesma forma; uma para cada porém sempre mantendo o sentido e a ordem da distribuição. Isto se repete até que as 36 cartas, numeradas de 0 a 35 , tenham sido distribuídas.

Como consequência fundamental desta forma de enumerar temos um resultado que verifica quais números os diversos subníveis do nível $k$, os estratos da enumeração, acumulam dentro de si. Este teorema é a conexão entre a enumeração proposta e a aritmética modular. Para se enunciar este teorema se fez necessário enumerar também os subníveis de tamanho $i$ dentro do nível $k$. No nível $k$, o fractal é formado por $n^{k-i}$ subníveis de tamanho $i$. Indexaremos estes subníveis de 0 até $n^{k-i}-1$, através de uma enumeração análoga a realizada no fractal. Para isto, chamaremos de $(i, j)$-subnível ao $j$-ésimo subnível de tamanho $i$ como indicado na Figura 11.

Desta forma, a enumeração dos subníveis de tamanho $i$ no nível $k+1$ se dá de forma indutiva a partir da enumeração dos subníveis de tamanho $i$ no nível anterior. A saber, a enumeração dos subníveis de tamanho $i$ do nível $k$ gera $n^{k-i}$ posições em cada uma das $n$ cópias deste nível dentro do nível $k+1$. No nível $k+1$, percorremos estas posições pelas cópias, esgotando uma por uma, a partir do topo e no sentido anti-horário com os números de 0 até $n^{k+1-i}-1$.

Teorema 1. Os subníveis de tamanho $i$ do nível $k$ equivalem as classes residuais dos inteiros módulo $n^{k-i}$, mais especificamente o $(i, j)$-subnível acumula dentro de si os inteiros congruentes a j módulo $n^{k-i}$.

\section{Demonstração 1.}

De fato, a forma com que percorremos a enumeração do fractal é análoga a forma como enumeramos os subníveis de tamanho $i$, girando no sentido anti-horário a partir do topo. Isto faz com que os primeiros $n^{k-i}$ números da enumeração entrem no topo dos $(i, j)$-subníveis. Em outras palavras, a enumeração entra no $(i, j)$-subnível pelo número $j$.

Além disso, um $(i, j)$-subnível se trata de uma posição entre os subníveis de tamanho $i$. A cada percurso por esta posição, a enumeração do fractal que entrou neste subnível pelo número $j$, só vai retornar a este subnível após passar pelo menos uma vez por todos os subníveis deste tamanho. Como temos $n^{k-i}$ subníveis de tamanho i e o $(i, j)$-subnível começa pelo número $j$, voltaremos a este mesmo $(i, j)$-subnível com os números $j+m . n^{k-i}$, onde $m$ varia de 1 até a máxima quantidade de vezes que percorremos todos os subníveis de tamanho i até que todo o $(i, j)$-subnivel esteja totalmente enumerado.

\section{ENUMERAÇÃO E NUMERAÇÃO/NOTAÇÃO POSICIONAL}

Na seção anterior, o termo posição serviu para estabelecer o processo indutivo. Nela, a forma com que determinamos as posições num nível depende da forma como o nível anterior foi enumerado, e quando pensamos em indexar um baricentro, estamos restritos a esgotar os pontos da figura de acordo com as posições, a partir do início, até chegarmos ao tal ponto. 


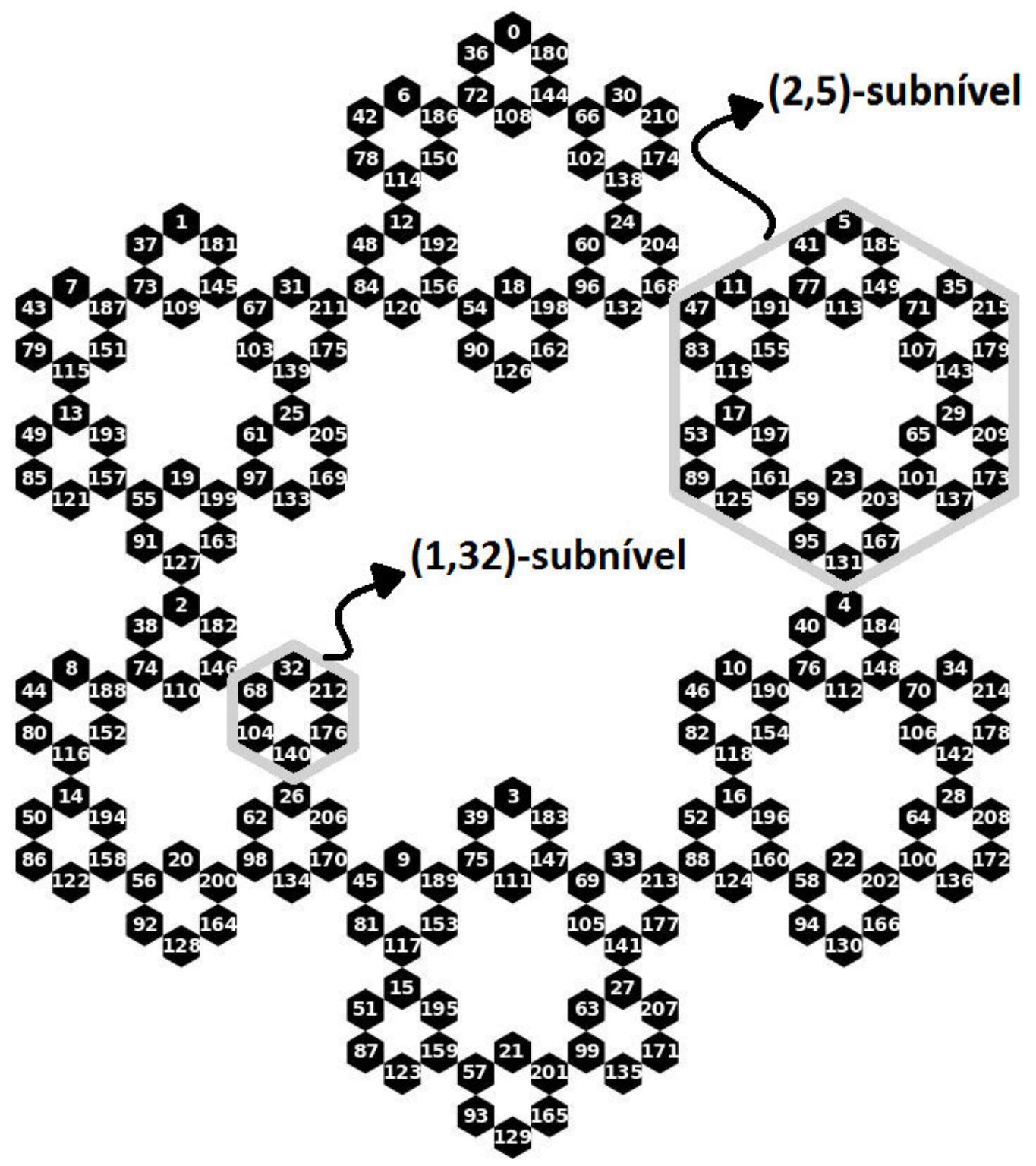

Figura 11: Enumeração do nível 3 do 6-gon. Em destaque com marcas cinzas o (1,32)-subnível e o $(2,5)$-subnível.

Na Figura 12 temos o 6-gon com um hexágono destacado. Pergunta: Qual número (índice na enumeração) será atribuído a este hexágono? Poderíamos pacientemente executar todos os passos da enumeração e verificar que é o 117, como podemos conferir na Figura 11.

Para contornar a varredura por posições até chegar ao ponto que se quer indexar, usaremos o artifício de olhar um $(i, j)$-subnível como um polígono de $n$-lados onde os vértices são os seus 


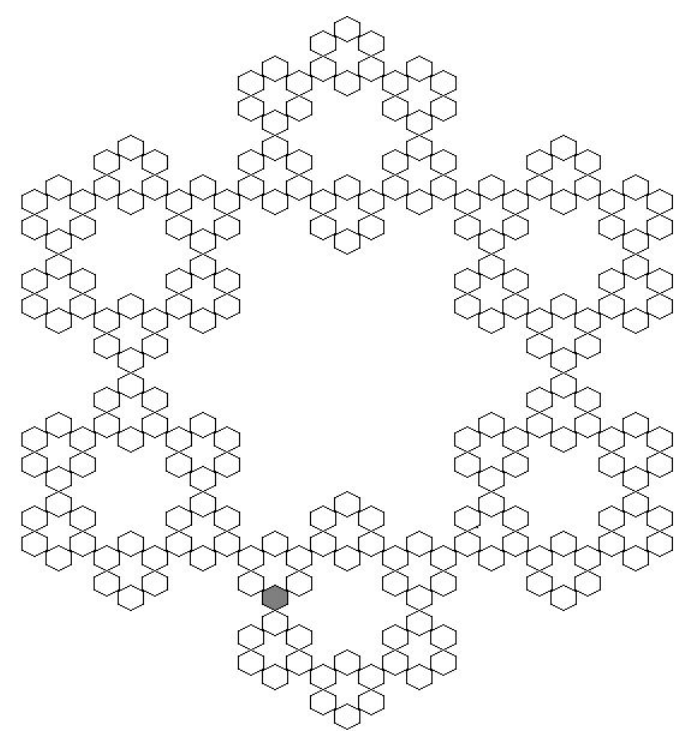

Figura 12: Qual número preencherá o hexágono destacado?

subníveis de tamanho $i-1$. Baseado nisto, determinaremos uma fórmula descritiva para o índice de um ponto de forma que para cada $0<i \leq k$ esta fórmula só dependa da posição geométrica de um subnível de tamanho $i-1$ como vértice de um subnível de tamanho $i$. A vantagem é que tal fórmula retorna facilmente o índice de um baricentro, além de responder ao problema inverso, isto é, ela também prevê onde cairá um número inteiro $d$ dentre os baricentros que formam o fractal.

Com um $(i, j)$-subnível sendo um polígono onde os vértices são os seus subníveis de tamanho $i-1$, rotulamos estes vértices a partir do topo e no sentido anti-horário de 0 até $n-1$.

Ilustremos esta ideia com o Hexágono de Sierpinski construído até o nível 4. Dado um número $0 \leq d \leq 6^{4}-1$, destaque no nível 4 o subnível de tamanho 3 que contém $d$, e seja $a_{4}$ o rótulo deste subnível como vértice do nível 4. Agora dentro deste $(3, j)$-subnível, destaque o subnível de tamanho 2 que contém $d$, e seja $a_{3}$ o rótulo deste subnível como vértice de um $(3, j)$-subnível. Continue, destacando no subnível de tamanho 2 já destacado, o subnível de tamanho 1 que contém $d$ e seja $a_{2}$ o rótulo deste vértice. Finalmente, destacaremos no tal subnível de tamanho 1 , o seu subnível de tamanho 0 que contém $d$, e teremos $a_{1}$.

Desta forma, para cada número $d$, temos uma sequência $\left(a_{1}, a_{2}, a_{3}, a_{4}\right)$ dos respectivos rótulos de $d$ em cada subnível $i$ ao qual ele se encontra. Vamos chamar esta sequência de Coordenadas de Sierpinski de $d$ ou simplesmente de coordenadas. Na Figura 13 estão destacada as coordenadas $(5,5,3,2)$ do nível 4 do hexágono.

De forma geral, com o $n$-gon construído até o nível $k$, cada $0 \leq d \leq n^{k}-1$ está associado as suas coordenadas $\left(a_{1}, a_{2}, \cdots, a_{k}\right)$, onde $a_{i} \in\{0, \cdots, n-1\}$, para todo $1 \leq i \leq k$. 


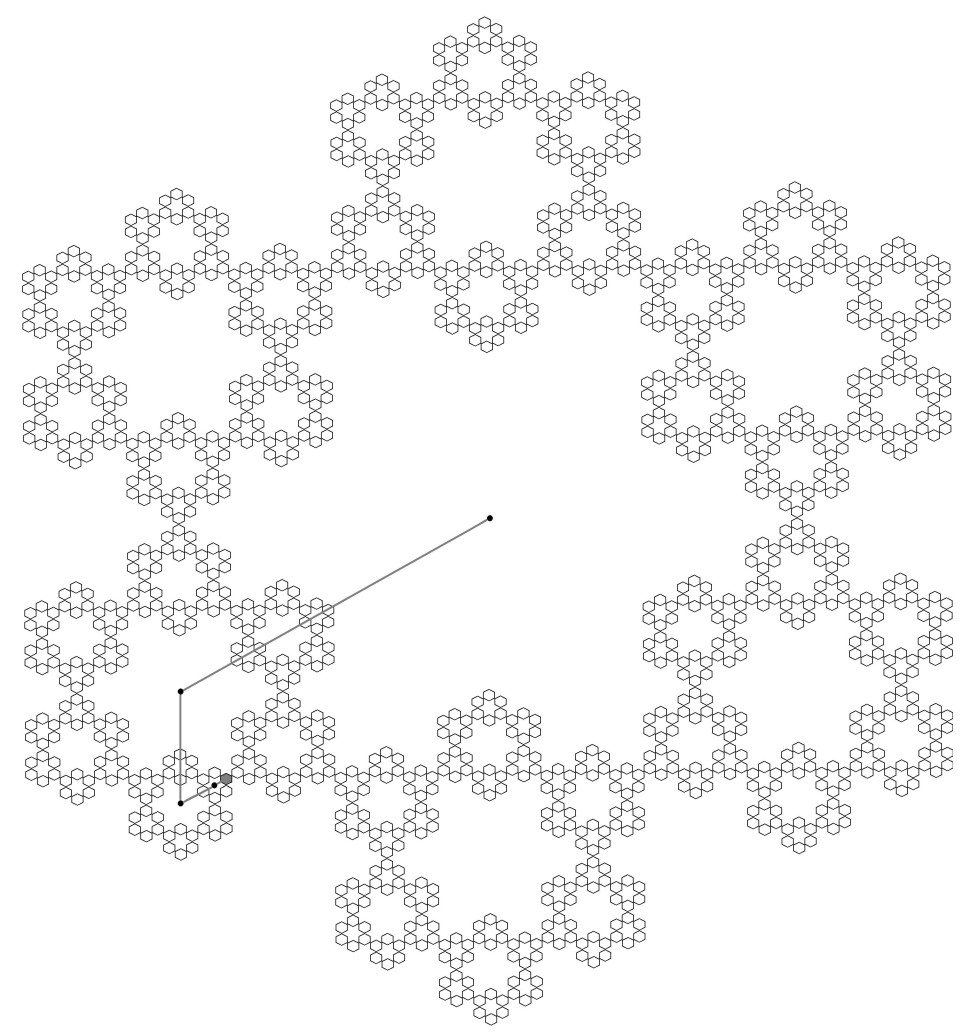

Figura 13: Um caminho partindo do centro da figura passa por todos os subníveis que contém o polígono destacado.

Pela Tabela 1 vemos facilmente que:

- $d=0$ está associado às coordenadas $(0,0,0, \cdots, 0)$. Esta é a posição do topo do fractal.

- Para representar outros valores seguidos de $d$, uma das coordenadas $a_{i}$ varia de 0 até $n-1$ e só depois ela volta a receber 0 para continuar a numeração.

- $a_{i-1}$ só é atualizado no momento em que $a_{i}$ volta a receber 0 .

Este processo é análogo ao que fazemos no sistema de numeração posicional de base $n$, onde o valor de um dígito só avança quando o dígito que vem em seguida volta a receber 0 . Nossa forma de numeração padrão é o sistema decimal, o sistema posicional de numeração de base dez. No sistema de numeração posicional de base $n$, utilizamos $n$ símbolos ou algarismos distintos. Por exemplo, na base 6 os símbolos são $0,1,2,3,4$ e 5. Neste tipo de representação, quando movemos um algarismo para a esquerda estamos multiplicando o seu valor por $n$. A Tabela 1 mostra o começo e o fim da enumeração do nível 4 do hexágono de Sierpinski. Observando com 
Tabela 1: Hexágono até o nível 4.

\begin{tabular}{r|c||r|c||r|c}
$\mathrm{d}$ & $\left(a_{1}, a_{2}, a_{3}, a_{4}\right)$ & $\mathrm{d}$ & $\left(a_{1}, a_{2}, a_{3}, a_{4}\right)$ & $\mathrm{d}$ & $\left(a_{1}, a_{2}, a_{3}, a_{4}\right)$ \\
0 & $(0,0,0,0)$ & 12 & $(0,0,2,0)$ & 1284 & $(5,5,4,0)$ \\
1 & $(0,0,0,1)$ & 13 & $(0,0,2,1)$ & 1285 & $(5,5,4,1)$ \\
2 & $(0,0,0,2)$ & 14 & $(0,0,2,2)$ & 1286 & $(5,5,4,2)$ \\
3 & $(0,0,0,3)$ & 15 & $(0,0,2,3)$ & 1287 & $(5,5,4,3)$ \\
4 & $(0,0,0,4)$ & 16 & $(0,0,2,4)$ & 1288 & $(5,5,4,4)$ \\
5 & $(0,0,0,5)$ & $\vdots$ & $\vdots$ & 1289 & $(5,5,4,5)$ \\
6 & $(0,0,1,0)$ & 1278 & $(5,5,3,0)$ & 1290 & $(5,5,5,0)$ \\
7 & $(0,0,1,1)$ & 1279 & $(5,5,3,1)$ & 1291 & $(5,5,5,1)$ \\
8 & $(0,0,1,2)$ & 1280 & $(5,5,3,2)$ & 1292 & $(5,5,5,2)$ \\
9 & $(0,0,1,3)$ & 1281 & $(5,5,3,3)$ & 1293 & $(5,5,5,3)$ \\
10 & $(0,0,1,4)$ & 1282 & $(5,5,3,4)$ & 1294 & $(5,5,5,4)$ \\
11 & $(0,0,1,5)$ & 1283 & $(5,5,3,5)$ & 1295 & $(5,5,5,5)$
\end{tabular}

atenção esta tabela, podemos perceber que ela se refere exatamente a passagem da base decimal para a base 6 , de números menores que $6^{4}$.

Por exemplo, no início da terceira coluna da Tabela 1 o número $1284=5 \cdot 6^{3}+5 \cdot 6^{2}+4 \cdot 6^{1}+0 \cdot 6^{0}$ cujas coordenadas são $(5,5,4,0)$. Este fato não é uma coincidência e vale em geral, como afirma o seguinte teorema:

Teorema 2. Na enumeração do $n$-gon construído até o nível $k$, se o número $d<n^{k}$ tem coordenadas $\left(a_{1}, a_{2}, \cdots, a_{k}\right)$, então os dígitos de $d$ em sua representação na base $n$ são exatamente $a_{1} a_{2} \cdots a_{k}$, isto é,

$$
d=a_{1} \cdot n^{k-1}+a_{2} \cdot n^{k-2}+\cdots+a_{k} \cdot n^{0}
$$

Demonstração 2. Se as coordenadas de d são $\left(a_{1}, a_{2}, \cdots, a_{k}\right)$, então $a_{i}$ se refere a posição do $(i-1, j)$-subnível que contém d como vértice de um subnível de tamanho $i$. Além disso, o número $a_{i}$ nos diz quantas vezes a enumeração deu uma volta completa de tamanho $n^{k-i}$ (passando por $n^{k-i}$ subníveis de tamanho $\left.i-1\right)$ a partir de $(i-1,0)$ até chegar em $(i-1, j)$.

A ideia da prova é: para cada $i=k, \cdots, 1$, transladar d para o $(i-1,0)$-subnível modificando sucessivamente as coordenadas $a_{k}, a_{k-1}, \cdots, a_{1}$.

- $d \in\left(k-1, a_{k}\right)$-subnível, logo transladando d para o $(k-1,0)$-subnível obtemos $d-a_{k}$ com posição $a_{k-1}$ no $(k-1,0)$-subnível;

- para transladar $d-a_{k}$ para o $(k-2,0)$-subnível temos que voltar $a_{k-1} n$. Logo $d-a_{k}-$ $a_{k-1}$ tem posição $a_{k-2}$ no $(k-2,0)$-subnível;

- $d-a_{k}-a_{k-1} n-a_{k-2} n^{2}$ é então o resultado da translação de d para o $(k-3,0)$-subnível e se encontra aí com posição $a_{k-3}$; 
- Seguindo indutivamente enquanto $i>1$, temos que $d-a_{k}-a_{k-1} n-a_{k-2} n^{2}-\cdots-a_{i} n^{k-i}$ é o resultado da translação de d para o $(i-1,0)$-subnível onde se encontra na posição $a_{i-1}$.

- Quando chegamos em $i=1$, temos $d-a_{k}-a_{k-1} n-a_{k-2} n^{2}-\cdots-a_{1} n^{k-1}$ como o resultado da translação de d para o (0,0)-subnível, isto é, $d-a_{k}-a_{k-1} n-a_{k-2} n^{2}-\cdots-a_{1} n^{k-1}=$ 0 .

A unicidade da representação num sistema de numeração posicional faz com que o Teorema 2 seja na verdade uma equivalência. Sendo assim, ele nos dá uma forma rápida de localizar a posição de um número $d$ entre os $n^{k}$ polígonos que formam o nível $k$ do fractal $n$-gon, isto é, podemos marcar $d$ na enumeração sem ter que percorrer os números anteriores. Por exemplo, voltando a Figura 11, por inspeção, partindo das coordenadas $\left(a_{1}, a_{2}, a_{3}\right)=(5,0,3)$ geramos a escrita na base $6,3 \cdot 6^{0}+0 \cdot 6^{1}+5 \cdot 6^{2}$ para o número 183 .

Além disso, a interpretação de $a_{i}$ como o número de voltas completas pelos $(i-1, j)$-subníveis, saindo do topo até chegar dentro do $(i, j)$-subnível onde $d$ se encontra, nos diz que podemos determinar os números que se acumulam no subnível de rótulo $a_{i}$ dentro do $(i, j)$-subnível de acordo com o seguinte corolário:

Corolário 1. Para um n-gon construído até o nível $k$, o subnível de tamanho $i-1$ na posição $a_{i}$ do $(i, j)$-subnível é o $\left(i-1, n^{k-i} a_{i}+j\right)$-subnível.

Por fim note que a Tabela 1 pode ser interpretada utilizando a imagem do nível 4 de construção do 6-gon. Na Figura 14 ilustramos isto colocando no centro de um $(i-1, j)$-subnível o número correspondente ao seu rótulo $a_{i}$ como vértice de um subnível de tamanho $i$. Observe que existem números em quatro escalas tipográficas diferentes, onde quanto maior é o valor de $i$, maior será a escala utilizada para representar os valores de $a_{i}$. Aqueles que indicam a coordenada $a_{4}$ estão em maior escala e os que representam $a_{1}$ em menor escala. Com este referencial, localize no $(3,1)$-subnível, o $(2, j)$-subnível na posição $a_{3}=5$. Por inspeção, podemos concluir que $j=$ $31=6^{4-3} \cdot 5+1$ como afirma o Corolário 1 .

\section{SOBRE A “DISTRIBUIÇÃO FRACTAL” DOS PRIMOS}

Por mais que a distribuição dos números primos na reta real nos leve a pensar numa distribuição aparentemente irregular, em nosso painel visual isto se dá de maneira organizada e equidistribuída em relação aos subníveis de mesmo tamanho. Por exemplo, no hexágono de Sierpinski construído até o nível $k$ observa-se que os números primos se acumulam equidistribuidamente em somente dois subníveis de tamanho $k-1$, aquele que acumula os números do tipo $6 m+1$, o $(k-1,1)$-subnível, e aquele que acumula os números do tipo $6 m+5$, o $(k-1,5)$-subnível, conforme podemos observar na Figura 15.

Observação 1. Estas figuras foram geradas através de um programa executável que criamos para a visualização de fractais n-gons enumerados e que permite aos usuários interatividade 


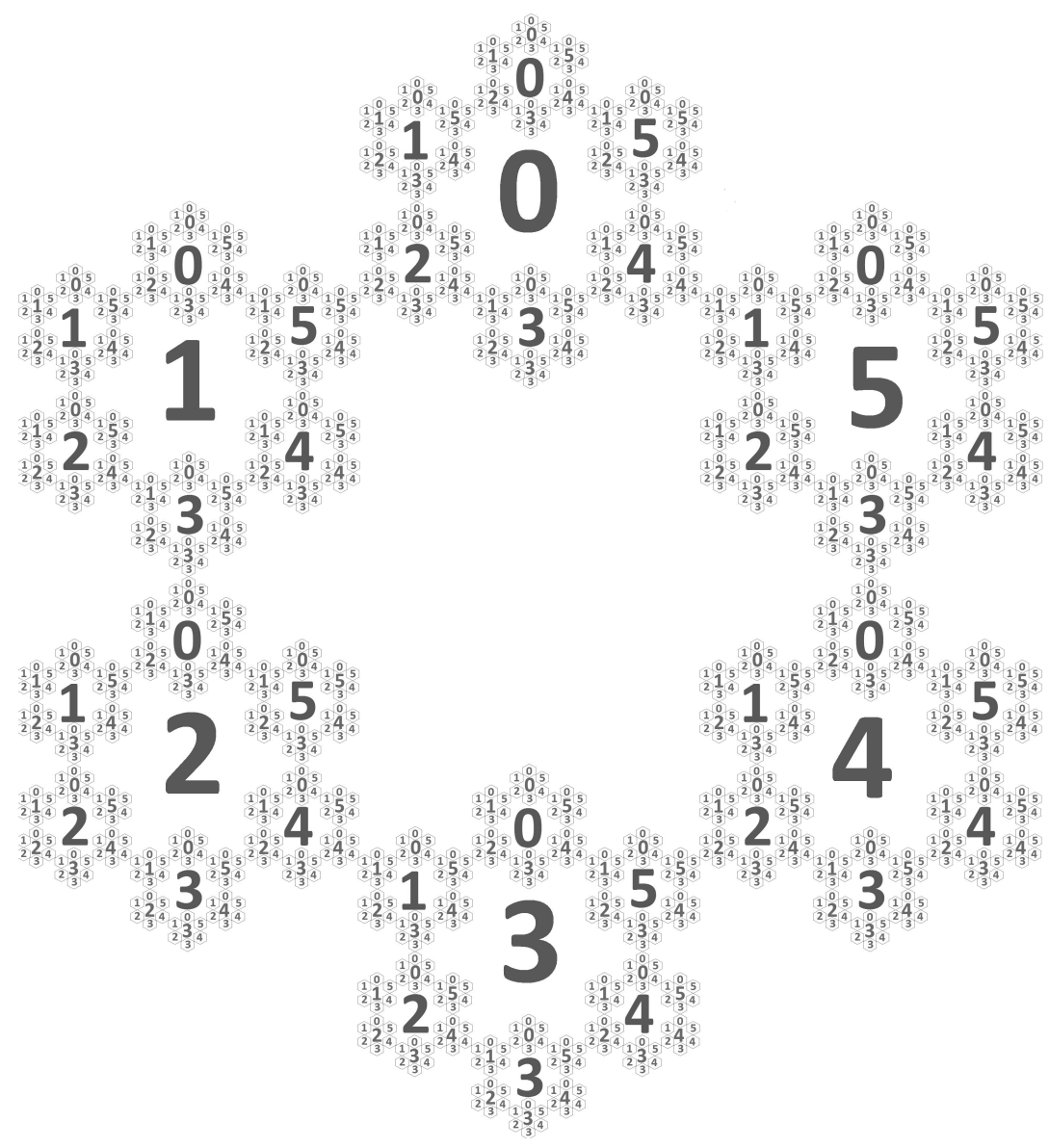

Figura 14: Representação geométrica da Tabela 1.
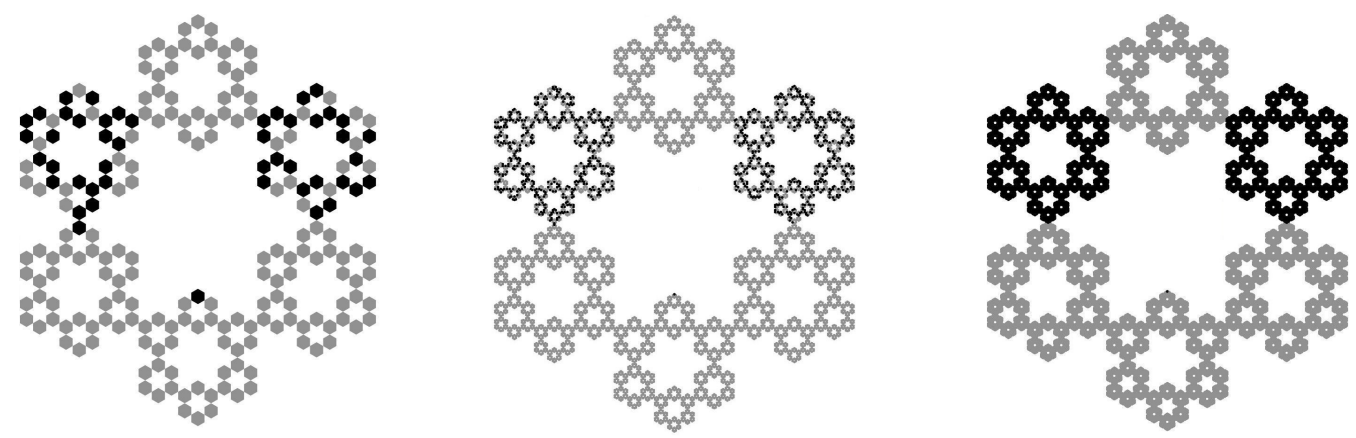

Figura 15: Em preto os números primos no intervalo $\left[0,6^{3}\right],\left[0,6^{5}\right]$ e $\left[0,6^{10}\right]$ respectivamente. 
para explorar a distribuição de qualquer sequência de números inteiros através da coloração dos pontos que representam tal sequência. Por uma escolha nossa, os pontos coloridos se sobrepõem aos outros, criando uma ilusão de densidade para a cor utilizada, porém através da aplicação de zooms consecutivos podemos ver a distribuição real.

A partir de qualquer outro fractal $n$-gon, analogamente ao que acontece na Figura 15, podemos inferir que os primos se localizam e se distribuem equilibradamente entre os $(i, j)$-subníveis para os quais $j$ é coprimo com $n$, o que é um reflexo de um importante teorema da Teoria Analítica dos Números, o Teorema dos Números Primos (doravante abreviado por TNP). Se $\pi(x)$ denota a função real de variável real que mede a quantidade de primos menor ou igual a $x$, o TNP nos diz que o comportamento assintótico da função $\pi(x)$ pode ser moldado pela função $x / \ln (x)$. Além disso, De la Vallée Poussin após provar o TNP, obteve refinamentos importantes sobre a taxa de crescimento da função $\pi_{n, a}(x)$ que mede o número de primos $p$ menores ou iguais a $x$ que são congruentes a $a$ módulo $n$, quando $1 \leq a<n$ e $m d c(a, n)=1$. Mais especificamente, podemos medir a taxa de crescimento das funções $\pi(x)$ e $\pi_{n, a}(x)$ através dos seguintes limites:

1. $\lim _{x \rightarrow \infty} \pi(x) / \frac{x}{\ln (x)}=1$ (TNP, conforme [6], página 156)

2. $\lim _{x \rightarrow \infty} \pi_{n, a}(x) / \frac{x}{\ln (x)}=\frac{1}{\phi(n)}$ ( De La Vallée Poussin, conforme [6], página 191)

onde $\phi(n)$ é a função de Euler e conta a quantidade de inteiros positivos menores do que $n$ que são coprimos com $n$. Observe que o resultado em 2 independe do número $a$.

No contexto da estratificação "residual" via congruências que estamos apresentando e utilizando a notação de De la Vallée Poussin, o Teorema 1 da seção 3, nos diz que:

3. A quantidade de primos no $(i, j)$-subnível do $n$-gon construído até o nível $k$ quando $n$ e $j$ são primos entre si, é dada por $\pi_{n^{k-i}, j}\left(n^{k}\right)$.

Observação 2. Podemos juntar os três itens acima para obter uma relação entre a distribuição dos primos entre as classes residuais $(\bmod n)$ e a distribuição dos primos em relação aos seus dígitos quando representados posicionalmente na base $n$, como veremos a seguir.

Seja $[p]_{n}=\left(a_{1}, a_{2}, \cdots, a_{k}\right)$ a representação do primo $p$ no sistema posicional de base $n$. O que o Teorema 2 da Seção 4 nos diz sobre o dígito $a_{k}$ ? Ele nos diz que $p$ está no $\left(k-1, a_{k}\right)$-subnível, e desta forma as possibilidades para os valores de $a_{k}$ são os inteiros não-negativos menores que $n$ que são coprimos com $n$. Assim, se $m d c(j, n)=1$, a probabilidade de $a_{k}=j$ dado que $p$ é primo é $\frac{1}{\phi(n)}$.

E o que podemos concluir sobre os outros dígitos de $p$ ? Como os outros dígitos estão associados aos $(i, j)$-subníveis com $i<k$, a aplicação de zooms consecutivos nos induz a pensar que o preto se equidistribue em todos os subníveis de tamanho $i$ dentro dos $(k-1, j)$-subníveis que contém primos. 


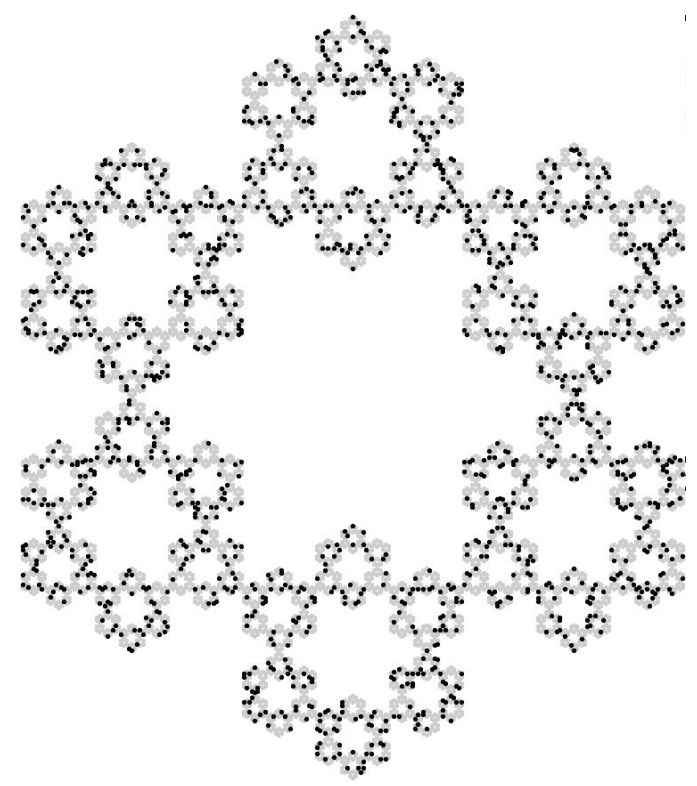

Figura 16: O (4,5)-subnível do nível 10 do Hexágono de Sierpinski obtido através de zooms consecutivos no 6-gon à direita da Figura 15. Os polígonos com números primos estão indicados em preto.

Então podemos inferir que os dígitos $a_{1}, \cdots, a_{k-1}$ de um número primo na base $n$, variam entre os inteiros não-negativos menores que $n$ de forma equilibrada. Este fato é um reflexo do Teorema de De la Vallée Poussin. De fato, os subníveis de tamanho $i-1$ dentro dos $(k-1, j)$-subníveis com $m d c(j, n)=1$ são exatamente as classes residuais módulo $n^{k-i+1}$ dos inteiros primos com $n$. Detalhadamente temos:

- $a_{i}$ se refere ao rótulo de um subnível de tamanho $i-1$ como vértice de um $(i, j)$-estrato;

- A quantidade de $(i, j)$-estratos em cada $(k-1)$-subnível é $n^{k-1-i}$;

- Se desejamos contar os primos, temos que olhar apenas para os $(i, j)$-estratos que estão dentro dos $\phi(n)$ subníveis de tamanho $k-1$ que contém primos. Assim, temos $\phi(n) \cdot n^{k-1-i}$ destes estratos e em todos eles $m d c(j, n)=1$;

- Do Corolário 1 , em cada um destes $(i, j)$-estratos que estamos interessados, vamos olhar para a coordenada $a_{i}$, ou seja, o $\left(i-1, n^{k-i} a_{i}+j\right)$-subnível;

- O Teorema 1 diz que o $\left(i-1, n^{k-i} a_{i}+j\right)$-subnível acumula dentro de si os inteiros menores do que $n^{k}$ que são congruentes a $a=n^{k-i} a_{i}+j$ módulo $m=n^{k-i+1}$, logo terá $\pi_{m, a}\left(n^{k}\right)$ primos; 
- Como $m d c(a, n)=1$, o Teorema de De Vallée Poussin nos diz que os primos que estamos interessados estão igualmente distribuídos nestes estratos para os diversos valores de $j$ possíveis e assim, a probabilidade de um primo menor que $n^{k}$ se encontrar na posição $a_{i}$ é:

$$
\frac{\phi(n) \cdot n^{k-1-i} \pi_{m, a}\left(n^{k}\right)}{\pi\left(n^{k}\right)} \sim \frac{\phi(n) \cdot n^{k-1-i}}{\phi(m)}
$$

- Pelas propriedades da função $\phi$ de Euler, $\frac{\phi(n)}{\phi\left(n^{k-i+1}\right)}=1 / n^{k-i}$, donde chegamos a probabilidade de $1 / n$.

Fixado um $0 \leq r<n$, o que estamos verificando nesta sequência de afirmações é que a longo prazo, ou seja para $k$ grande, a probabilidade de um primo na enumeração do nível $k$ do $n$-gon ter coordenada $a_{i}=r$, ou de outra forma, a probabilidade de um primo quando representado na base $n$ ter seu $i$-ésimo dígito igual a $r$, é dada por $P\left(a_{i}=r \mid p\right.$ primo $)=1 / n$.

\subsection{Primos de Sophie Germain}

Para ilustrar a regularidade de outras listas de números inteiros positivos dentro destes painéis vamos utilizar os Primos de Sophie Germain. Um número primo $p_{s g}$ é dito primo de Sophie Germain se o número $p_{q}=2 p_{s g}+1$ também é um número primo [2]. Por exemplo, 3 e $2 \cdot 3+1=7$ são primos, logo 3 é um primo de Sophie Germain. Sobre os primos de Sophie Germain foi possível detectar as propriedades a seguir que ilustram o potencial didático destes painéis.

- Propriedade 1: Estes primos se localizam apenas dentro do $(i, 5)$-subnível no hexágono de Sierpinski.

Comparando as distribuições dos primos e dos primos de Sophie Germain no 6-gon (Vide Figura 17), notamos uma tendência dos primos de Sophie Germain de se localizarem somente no subnível $(i, 5)$ contrastando com os primos que estão no $(i, 1)$-subnível. De fato, se $p_{s g}=6 k+1$ então $p_{q}=2 \cdot p_{s g}+1=3(4 k+1)$ não pode ser primo.

A Figura 18 exibe a distribuição dos primos de Sophie Germain para diferentes n-gons com $n$ ímpar. Destacamos com uma marca de cruz o subnível com números congruentes a $\frac{n-1}{2} \bmod n$, e notamos que estes subníveis tinham no máximo 1 primo de Sophie Germain. A partir disto conjecturamos a Propriedade 2 que posteriormente foi provada.

- Propriedade 2: Seja $n$ um número ímpar, não existem primos de Sophie Germain no $\left(\frac{n-1}{2}, k-1\right)$-subnível do $n$-gon. A exceção é o caso em que $\frac{n-1}{2}$ é um primo de Sophie Germain, e neste caso este será o único primo nesta contração.

De fato, se $p_{s g}$ é um primo congruente $\frac{n-1}{2}(\bmod n)$, então $p_{q}=2 \cdot p_{s g}+1 \equiv n(\bmod n)$. 


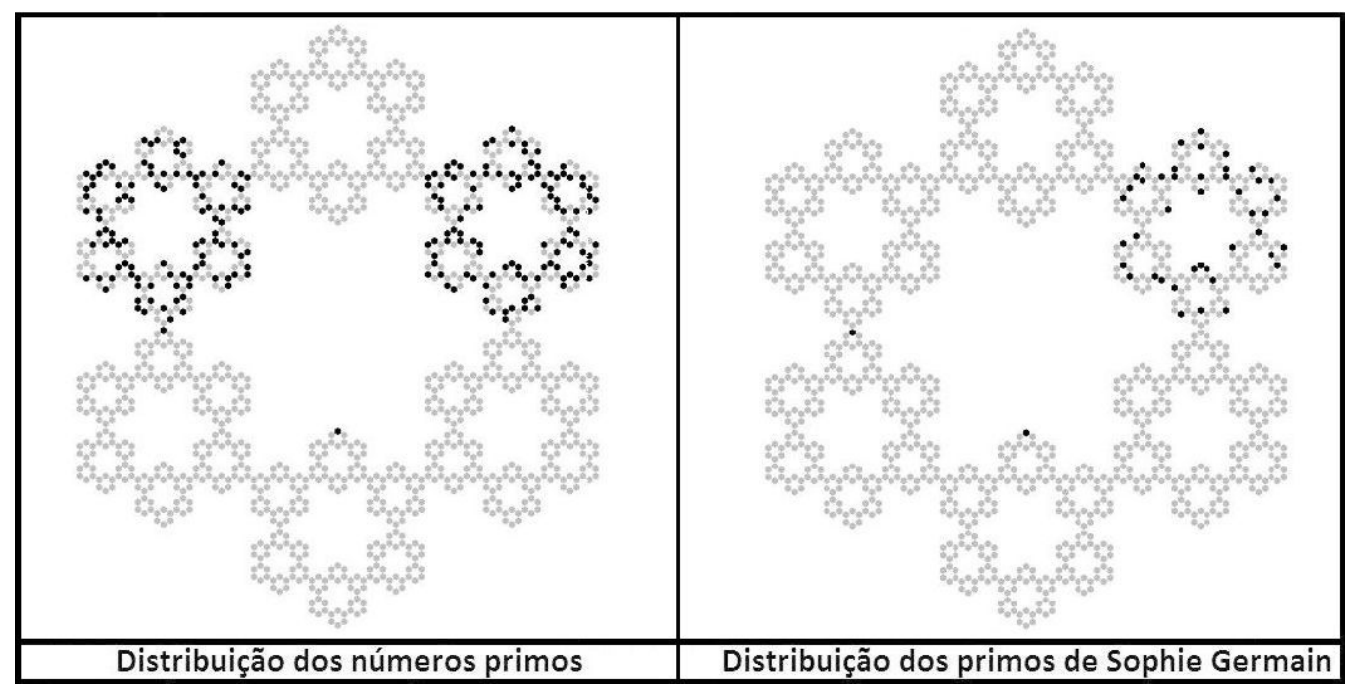

Figura 17: Em preto, a distribuição dos números primos e dos primos de Sophie Germain no intervalo $[0,1295]$.

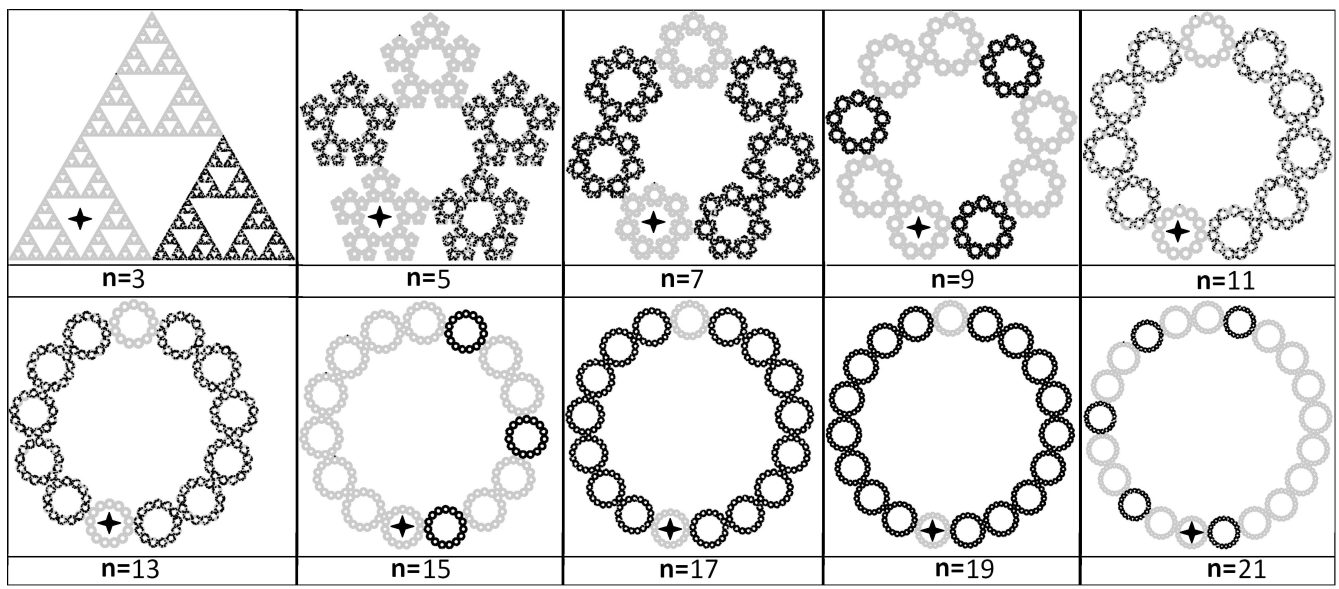

Figura 18: Em preto os números primos de Sophie Germain, em diferentes fractais n-gons. As contrações com marcação se referem a classe de congruência $\frac{n-1}{2} \bmod n$.

\section{CONSIDERAÇÕES FINAIS}

Nos últimos anos, o uso de ambientes computacionais se tornou um importante auxiliar para o processo de ensino e aprendizado. Ao proporcionar uma melhor interface por meio do processamento de imagens e da interatividade do usuário, estas tecnologias tornaram a visualização matemática uma área a ser explorada, potente com novas técnicas como suporte na construção de novos exemplos, na verificação de conjecturas ou mesmo no auxílio de demonstrações. No artigo de 2003, "Visible Structures in Number Theory" [1], Peter Borwein e Loki Jorgenson dis- 
cutem como a visualização através do uso de computadores pode auxiliar no estudo da teoria dos números ao fazer uso de ferramentas gráficas interativas. Nas palavras dos autores: "nos concentramos nos casos em que a imagem certa sugere o 'teorema certo', ou onde indica uma estrutura que não se esperava, ou onde existe a possibilidade de 'prova visual'.'(De acordo com Borwein, 2001, p. 897, tradução nossa).

Durante o projeto de iniciação científica que deu origem a este trabalho desenvolvemos uma série de scripts em linguagem Python que foram usados para a elaboração de um programa executável para a visualização de fractais $n$-gons enumerados. O download de tais executáveis pode ser feito a partir do Google Drive na nota de rodapé ${ }^{2}$.

Este programa pode ser rodado em Windows 32 e 64 bits e em Mac OSx, e pela forma com que os executáveis foram gerados, não há a necessidade de uma instalação. Sua interface foi pensada para ser amigável a usuários leigos em programação, admitindo a adição de listas de números escritas em arquivos de texto no formato ".txt". No entanto ele facilmente admite expansões em formato de scripts. Também foi criada uma biblioteca para a linguagem de programação Python que pode ser baixada em Github ${ }^{3}$.

Além da distribuição dos primos, este programa permite visualizar outras listas de inteiros na tentativa de detectar padrões dentro desta estratificação, verificar visualmente padrões conhecidos na literatura ou ainda traduzir algumas conjecturas em termos da enumeração fractal. Por exemplo, em várias construções de $n$-gons construídos até o nível $k$ e com primos destacados em cinza, percebemos que cada $(k-1, j)$-subnível com $m d c(j, n)=1$ contém pelo menos um ponto cinza. Quando $k=2$, este fato equivale à conjectura $p(n)<n^{2}$, onde $p(n)=\max \{p(n, j)\}$ e para $m d c(j, n)=1, p(n, j)$ é o menor primo no $(1, j)$-subnível (Vide página 312 do livro "Números primos, amigos que causam problemas" de Paulo Ribenboim [7]). Na página 360, aparece também uma conjectura devido a Sierpinski que em termos do segundo nível de um $n$ gon, afirma que seguindo a enumeração, cada volta completa deve necessariamente passar por um ponto cinza.

\title{
AGRADECIMENTOS
}

O presente trabalho foi realizado com o apoio do IBGE. Os autores agradecem ao programa de bolsas PIBIC-IBGE da Graduação em Estatística da Escola Nacional de Ciências Estatísticas.

\begin{abstract}
In this work we have built a visual enumerated display using fractals of the type Sierpinski $n$-gons [8] with the purpose of analyzing some sequences of integers, mainly the sequence of prime numbers and some of their classic sequences. This visual structure generates a stratification of $\mathbb{Z}$ that has a stable connection with modular arithmetic, thus becoming a helpful visualisation display for objects and results of the number theory. Inspired by the construction of the Sierpinski Triangle through the Pascal Triangle and Ulam's work
\end{abstract}

\footnotetext{
${ }^{2}$ Local de donwload dos executáveis: https://tinyurl.com/ybcx8n8d.

${ }^{3}$ Link da biblioteca para Python 2: https://github.com/IsaacVsRodrigues/estratificar_fractal.
} 
on the spiral of primes [9], this enumeration emerged naturally from the computational generation of fractals $n$-gons where we chose as a strategy the deterministic algorithm cited by Steven Schlicker and Kevin Dennis [8].

Keywords: congruences, prime numbers, $N$-gons, Sierpinski fractal.

\section{REFERÊNCIAS}

[1] P. Borwein \& L. Jörgenson. Visible structures in number theory. The American Mathematical Monthly, 108(10) (2001), 897-910.

[2] H. Dubner. Large Sophie Germain primes. Mathematics of Computation, 65(213) (1996), 393-396.

[3] C.A.d.S. Fusco \& S.P. Coelho. Um pouco da teoria dos números: da antiguidade até os dias atuais. Ensino da Matemática em Debate, 1(2) (2014).

[4] B.B. Mandelbrot. "The fractal geometry of nature". Henry Holt and Company (1983).

[5] C. Pomerance. The search for prime numbers. Scientific American, 247(6) (1982), 136-147.

[6] P. Ribenboim. "Números Primos - Velhos Mistérios e Novos Recordes". IMPA (2001).

[7] P. Ribenboim. "Números primos, amigos que causam problemas". SBM (2005).

[8] S. Schlicker \& K. Dennis. Sierpinski n-gons. Pi Mu Epsilon Journal, 10(2) (1995), 81-89.

[9] M.L. Stein, S.M. Ulam \& M.B. Wells. A visual display of some properties of the distribution of primes. The American Mathematical Monthly, 71(5) (1964), 516-520.

[10] A.B.P. Zavala. "O Estudo de Funções Exponenciais e Logarítmicas Motivada Pela Geometria Fractal". Master's thesis, Universidade Federal do Paraná, Curitiba, PR (2007). 